\title{
IMPLEMENTASI ALGORITMA MAXIMAL SHIFT PADA APLIKASI MANFAAT TANAMAN BAGI KESEHATAN MANUSIA BERBASIS ANDROID
}

\author{
Abdul Rahman Pohan', Nelly Astuti Hasibuan², A. M. Hatuaon Sihite, SE, MM³ \\ Program Studi Teknik Informatika STMIK Budi Darma, Medan, Indonesia \\ Email: abdulrahmanpohan32@gmail.com
}

\begin{abstract}
Abstrak
Sebelum datangnya penyakit ada baik nya manusia mencegah nya, banyak tumbuh jenis tanaman yang bermanfaat bagi kesehatan, tetapi begitu juga beragam banyak nya jenis tanaman dan manfaat nya masing-masing sehingga susah untuk di mengerti mana yang bermanfaat untuk kesehatan mana yang tidak bermanfaat untuk kesehatan.Untuk mempermudah pencarian manfaat tanaman bagi kesehatan manuisa ini dirancang dengan menggunakan algoritma Maximal Shift, dimana algoritma ini sebagai solusi dalam pencarian manfaat tanaman bagi kesehatan manuisa dengan terbatasnya ukuran layar smartphone yang dimiliki, maka sangat diperlukan string matching sebagai suatu proses dalam pencarian.Aplikasi pencarian manfaat tanaman bagi kesehatan manusia berbasis android ini dirancang dengan menggunakan Eclipse Juno Dalam pengembangan aplikasi ini menggunakan bahasa pemograman Java.
\end{abstract}

Kata kunci : Maximal Shift, String Matching, Aplikasi Manfaat Tanaman, Berbasis Android

\section{Abstract}

Before the arrival of disease, it is good for humans to prevent it, many plants grow that are beneficial to health, but so are the many diverse types of plants and their respective benefits so that it is difficult to understand which are beneficial for health which are not beneficial for health. To facilitate the search for plant health benefits for human health, it was designed using the Maximal Shift algorithm, where this algorithm as a solution in searching for plant health benefits for human health with the limited screen size of smartphones owned, string matching is needed as a process in the search. Application search for the benefits of plants for human health based on Android was designed using Eclipse Juno. In the development of this application using the Java programming language.

Keywords: Maximal Shift, String Matching, Application of Plant Benefits, Based on Android

\section{PENDAHULUAN}

Sakit atau penyakit terkadang datang dengan tiba-tiba, tidak mengenal waktu, tidak ada aba-aba, atau gejala sebelumnya, itu yang sering membuat seseorang bisa menjadi panik ketika salah seorang anggota keluarga mereka mendadak sakit. Apalagi kalau itu terjadi pada tengah malam, atau ketika berada jauh dari rumah sakit, tentu agak sulit mencari pertolongan secara cepat.

Jenis penyakit sekarang juga bermacam-macam, sehingga juga butuh obat dan penanganan yang berbeda-beda pula. Kesehatan merupakan suatu hal yang sangat penting dalam kehidupan. Kalau tubuh manusia sakit maka segala aktifitas pekerjaan manusia akan terkendala. Maka itu kita harus menjaga tubuh agar tetap sehat. Akan tetapi sekuat apapun kita berusaha untuk menjaga kesehatan, terkadang manusia akan sakit juga.

Tapi kalau manusia mau belajar dari alam, manusia akan menyadari bahwa Tuhan itu maha adil, setiap kali dia menguji hamba-nya dengan penyakit, Tuhan sudah menyediakan obat atau penangkal nya, hanya saja sebagian manusia kurang mengetahui, bahwa disekitar manusia sebenarnya banyak sekali berbagai jenis tanaman yang bisa dijadikan obat dari bermacam penyakit. Selain efektif dan murah pengguna tanaman obat, relatif aman karena nyaris tidak menyebabkan efek samping.

Sebelum datangnya penyakit adabaiknya manusia mencegahnya, disekeliling tempat tinggal manusia banyak tumbuh jenis tanaman yang bermanfaat bagi kesehatan manusia, karena itu masyarakat bias mengusahakan sendiri untuk mencoba menanam tanaman tersebut dipekarangan, contohnya seperti jenis tanaman sayur-sayuran, tanaman buah-buahan, dan tanaman obat-obatan yang bias secara langsung berguna bagi kehidupan masyarakat itu sendiri.

Disini penulis ingin memakai algoritma String matching. Algoritma String matching sendiri berfungsi untuk melakukan pencarian suatu String baik berupa pattren ataupun teks. Pada program ini pengguna dapat menggunakan nya dengan cara memasukan suatau pattren atau teks untuk mencari manfaat tanaman kesehatan bagi manusia.

String matching adalah sebuah subjek yang banyak digunakan dalam lingkup pencarian teks. Algoritma-algoritma String matching menjadi komponen dasar yang diaplikasi pada berbagai piranti lunak dan dapat ditemukan pada hampir semua jenis sistem operasi[1]. Selain itu, algoritma-algoritma String matchingmempengaruhi metode pemrograman yang menjadi pola/acuan dalam bidang lainnya di computer science (baik sistem maupun perancangan piranti lunak).

Salah satu algoritma String matching adalah algoritma Maximal Shift adalah algoritma yang mencari pola dalam teks dengan cara pola dicari dari karakter yang memiliki nilai minShift yang terbesar hingga minShift yang terkecil. Sunday merancang sebuah algoritma dimana karater pola yang satu akan menyebabkan pergeseran yang lebih besar dan yang satu lainnya menyebabkan pergeseran yang lebih pendek. Tahapan proses dari algoritma Maximal shift terdiri dari memilah karakter pola dalam urutan penurunan pergeseran, membangun badcharaters shift dan fungsi good-suffix Shif. Fungsi tersebut disesuaikan denganurutan scanning karakter pola. 


\section{TEORITIS}

\subsection{String Matching}

String matching adalah proses pencarian semua kemunculan query yang selanjutnya disebut pattern ke dalam string yang lebih panjang (teks)[2]. Pattern di lambangkan dengan $\mathrm{x}=\mathrm{x}[0 . . \mathrm{m}-1]$ dan panjang nya adalah $\mathrm{m}$. Teks dilambangkan dengan $y=y[0 \ldots n-1]$ dan panjangnya adalah $n$. String Matching dirumuskan sebagai berikut:

$$
\begin{aligned}
& \mathrm{x}=\mathrm{x}[0 \ldots \mathrm{m}-1] \\
& \mathrm{y}=\mathrm{y}[0 \ldots \mathrm{n}-1] \\
& \text { Dimana }: \mathrm{x} \text { adalah pattern } \\
& \mathrm{m} \text { adalah panjang pattern }
\end{aligned}
$$

y adalah teks

$\mathrm{n}$ adalah panjang teks

Kedua string terdiri dari sekumpulan karakter yang disebut alfabet yang dilambangkan dengan $\Sigma$ (sigma) dan mempunyai ukuran $\sigma$ (tao). String matching dibagi menjadi dua, yakni exact matching dan heuristic atau statistical matching.

String matching adalah pencarian sebuah pattern pada sebuah teks. Prinsip kerja algoritma string matching adalah sebagai berikut:

1. Memindai teks dengan bantuan sebuah window yang ukurannya sama dengan panjang pattern.

2. Menempatkan window pada awal teks.

3. Membandingkan karakter pada window dengan karakter dari pattern. Setelah pencocokan (baik hasilnya cocok atau tidak cocok), dilakukan shift ke kanan pada window. Prosedur ini dilakukan berulang-ulang sampai window berada pada akhir teks. Mekanisme ini disebut mekanisme sliding-window.

Algoritma string matching mempunyai tiga komponen utama yaitu:

1. Pattern, yaitu deretan karakter yang akan dicocokkan dengan teks, dinyatakan dengan $x[0 . . m-1]$, panjang pattern dinyatakan dengan $\mathrm{m}$.

2. Teks, yaitu tempat pencocokan pattern dilakukan, dinyatakan dengan y[0..n-1], panjang teks dinyatakan dengan $n$.

3. Alfabet, yang berisi semua simbol yang digunakan oleh bahasa pada teks dan pattern, dinyatakan dengan $\Sigma$ dengan ukuran dinyatakan dengan ASIZE.

\subsection{Algoritma Maximal Shift}

Algoritma Maximal Shift adalah algoritma yang mencari pola dalam teks dengan cara pola dicari dari karakter yang memiliki nilai minShift yang terbesar hingga minShift yang terkecil. Sunday merancang sebuah algoritma dimana karater pola yang satu akan menyebabkan pergeseran yang lebih besar dan yang satu lainnya menyebabkan pergeseran yang lebih pendek[4]. Tahapan proses dari algoritma Maximal shift terdiri dari memilah karakter pola dalam urutan penurunan pergeseran, membangun bad-charaters shift dan fungsi good-suffix Shif, fungsi tersebut disesuaikan dengan urutan scanning karakter pola.

\begin{tabular}{|c|c|c|c|c|c|c|c|c|}
\hline$I$ & 0 & 1 & 2 & 3 & 4 & 5 & 6 & 7 \\
\hline$x[\mathrm{i}]$ & $\mathrm{G}$ & $\mathrm{C}$ & $\mathrm{A}$ & $\mathrm{G}$ & $\mathrm{A}$ & $\mathrm{G}$ & $\mathrm{A}$ & $\mathrm{G}$ \\
\hline $\operatorname{minShift}[i]$ & 1 & 2 & 3 & 3 & 2 & 2 & 2 & 2 \\
\hline
\end{tabular}

\subsection{Langkah-langkah Proses Algoritma Maximal Shift}

Proses pertama adalah prosedur perhitungan nilai minShift karakter pola yang akan digunakan untuk proses pengurutan. Dapat dilihat pada Tabel 1.

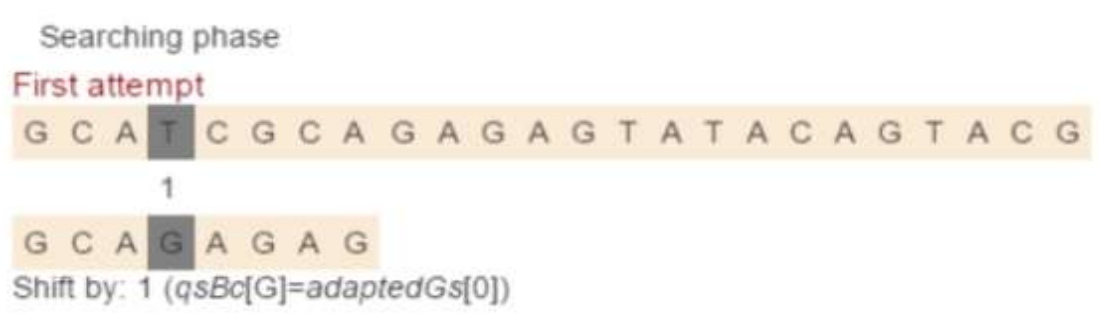




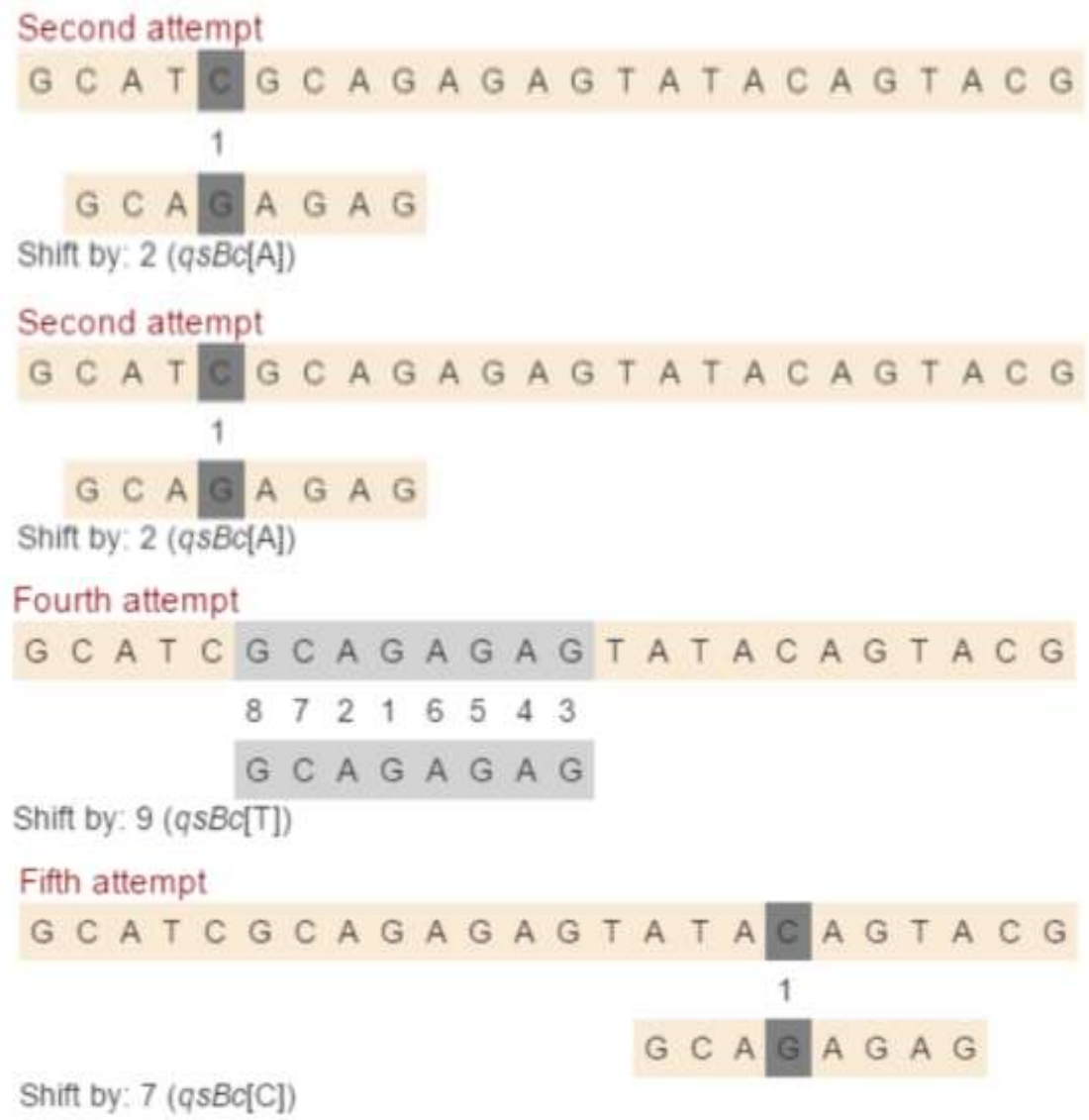

Gambar 1. Tahap pencarian algoritma Maximal Shift.

\subsection{Tanaman Yang Akan Digunakan}

1. Belimbing

Buah belimbing atau Averrhoa carambola merupakan buah tropis berwarna kuning keemasan dengan rasa dan bentuk seperti bintang yang khas. Untuk mengonsumsi buah ini, Anda tak perlu mengupasnya. Cukup dicuci bersih dan dipotong sesuai selera, lalu Anda bisa menikmatinya sebagai hidangan salad buah, acar, atau jus buah. Tak hanya dinikmati sebagai hidangan pencuci mulut, Anda juga perlu mengetahui beragam kandungan dan manfaat belimbing bagi kesehatan tubuh.

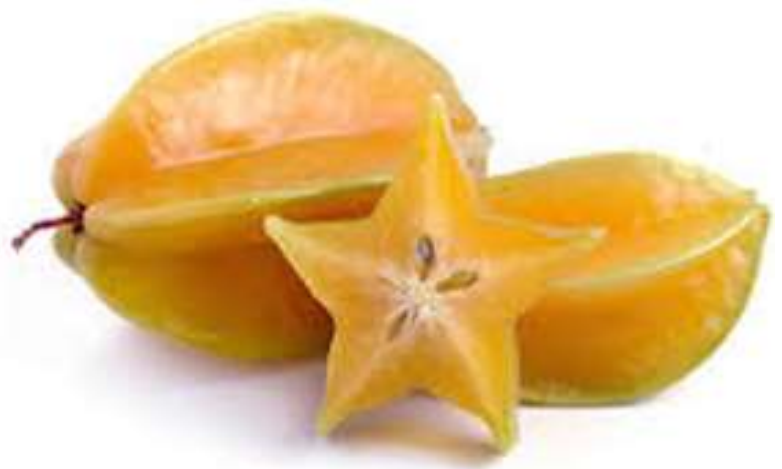

Gambar 2. Buah Belimbing

\section{ANALISA DAN PEMBAHASAN}

Sebelum datangnya penyakit ada baik nya manusia mencegah nya, banyak tumbuh jenis tanaman yang bermanfaat bagi kesehatan, tetapi begitu juga beragam banyak nya jenis tanaman dan manfaat nya masing-masing sehingga susah untuk di mengerti mana yang bermanfaat untuk kesehatan mana yang tidak bermanfaat untuk kesehatan. Oleh karena itu Algoritma Maximal Shift dapat diterapkan dalam pencarian Manfaat Tanaman bagi kesehatan manusia berbasis android. Hal itu guna untuk mempermudah pencarian dari memilih karakter pola dalam urutan penurunan pergeseran. Proses pencarian manfaat tanaman dilakukan dengan memasukan nama tanaman pada 
kolom pencarian yang telah tersedia pada aplikasi tersebut. Jika tanaman yang dicari pada kolom pencarian tersebut ditemukan, maka akan ditampilkan manfaat dari tanaman tersebut. Manfaat tanaman dikumpulkan dengan cara mencari sebuah referensi yang ada pada buku kemudian dikumpulkan dan disimpan pada database.

Pencarian manfaat tanaman bagi kesehatan manuisa ini dirancang dengan menggunakan algoritma Maximal Shift, dimana algoritma ini sebagai solusi dalam pencarian manfaat tanaman bagi kesehatan manuisa, karena banyaknya macam-macam tanaman sehingga sangat sulit untuk menampilkan manfaat tanaman itu sendiri. Tidak hanya itu, dengan terbatasnya ukuran layar smartphone yang dimiliki, maka sangat diperlukan string matching sebagai suatu proses dalam pencarian. Dimana dalam algoritma string matching manfaat tanaman bagi kesehatan manuisa akan lebih sedikit karena adanya proses pengecekan berdasarkan pattern.

Aplikasi pencarian manfaat tanaman bagi kesehatan manusia berbasis android ini dirancang dengan menggunakan Eclipse Juno. Eclipse adalah suatu IDE (Integrated Development Environment) pengembang aplikasi pada android. Dalam pengembangan aplikasi ini menggunakan bahasa pemograman Java.

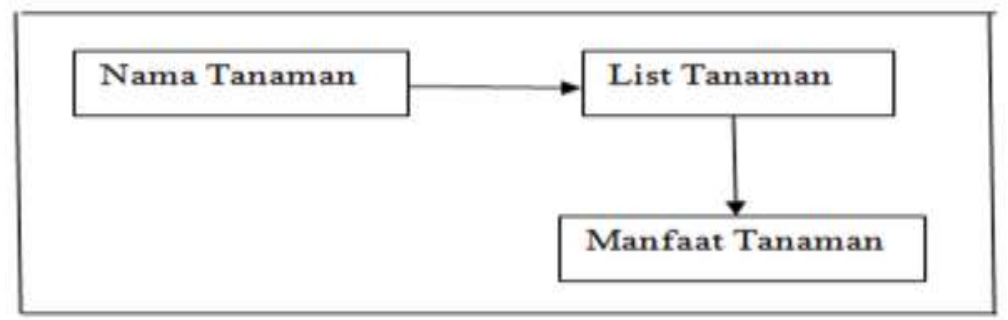

Gambar 3. Ilustrasi Anailisa

\subsection{Proses Maximal shift}

Proses pertama adalah menghitung nilai minshift karakter pada pola yang akan digunakan untuk proses pengurutan, seperti pada Tabel 2.

Tabel 2. Nilai minShift pada Algoritma Maximal Shift

\begin{tabular}{ccccc}
\hline I & 0 & 1 & 2 & 3 \\
Char & $\mathrm{L}$ & $\mathrm{E}$ & $\mathrm{N}$ & $\mathrm{G}$ \\
MinShift [i] & 1 & 2 & 3 & 4 \\
\hline
\end{tabular}

\section{Langkah 1:}

\begin{tabular}{|c|c|c|c|c|c|c|c|}
\hline $\mathrm{L}$ & $\mathrm{E}$ & $\mathrm{N}$ & $\mathrm{G}$ & $\mathrm{K}$ & $\mathrm{E}$ & $\mathrm{N}$ & $\mathrm{G}$ \\
\hline
\end{tabular}

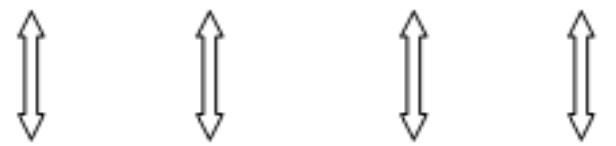

\section{Exact match}

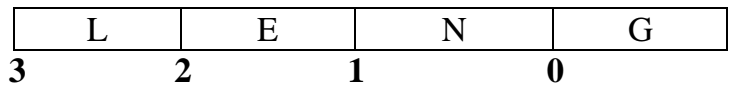

I : : 0

Selisih: 4

Geser : 0

\section{IMPLEMENTASI}

Adapun hasil aplikasi yang dirancang pada implementasi algoritma maximal shift pada aplikasi manfaat tanaman bagi kesehatan manusia berbasis android sebagai berikut: 
Keterangan :

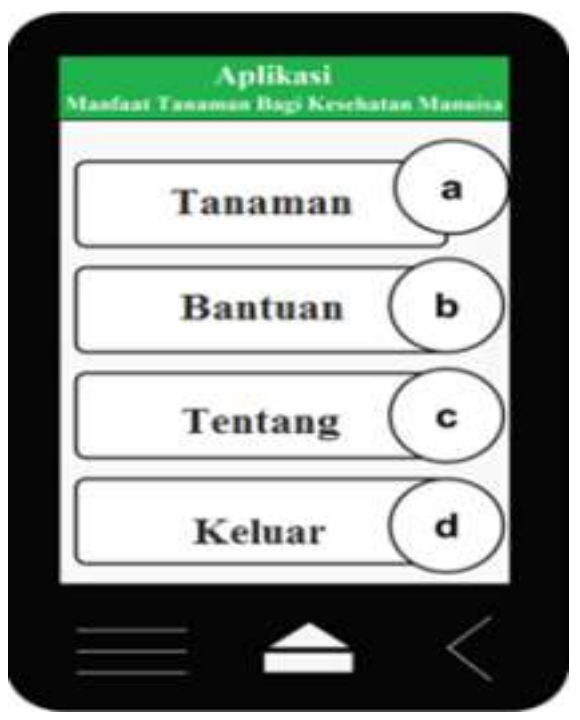

Gambar 3. Rancangan Form Menu Utama

a.Menu Pencarian untuk mencari manfaat tanaman bagi kesehatan manusia.

b.Menu Bantuan untuk menampilkan bantuan atau petunjuk penggunaan aplikasi.

c.Menu Tentang untuk menampilkan profil dari si pembuat aplikasi.

d.Menu Keluar untuk keluar dari menu utama. berikut :

Berikut ini adalah hasil pencarian kata pada Manfaat Tanaman. Hasil pencarian dapat dilihat pada tabel 4.1

Tabel 3. Tabel Hasil Pengujian

\begin{tabular}{lll}
\hline No Kata Yang di Cari & \multicolumn{1}{c}{ Status } & \multicolumn{1}{c}{ Hasil Pencarian } \\
\hline \multirow{3}{*}{1} & & 1. Meningkatkan produksi darah merah \\
& \multirow{2}{*}{ Leng Keng } & 2. Memulihkan Stamina \\
& & 3. Menyehatkan usus \\
& & 4. Melancarkan buang air kecil \\
& & 5. Sebagai obat insomnia \\
\hline
\end{tabular}

Keterangan :

1.No adalah nomor urut data pada listview

2.Cari Tanaman adalah Manfaat Tanaman yang dicari

3.Status adalah keterangan setelah proses pencarian dilakukan

4.Hasil Pencarian adalah Manfaat yang dihasilkan dari proses pencarian yang dilakukan oleh user.

\section{KESIMPULAN}

Berdasarkan hasil analisa bab - bab sebelumnya maka penulis dapat menarik sebuah kesimpulan, dimana kesimpulan tersebut nanti dapat kiranya dapat berguna bagi pembaca, sehingga penulisan sikripsi ini dapat lebih berguna dan bermanfaat. Adapun kesimpulan-kesimpulan tersebut antara lain sebagai berikut :

1. Proses pencarian Manfaat Tanaman dapat dilakukan dengan waktu lebih singkat dengan menerapkan algoritma Maximal Shift

2. Algoritma Maximal Shift dapat diterapkan pada proses pencarian Manfaat Tanaman

3. Rancangan aplikasi Manfaat Tanaman berbasis android menghasilkan tampilan antar muka sederhana dan tampilan output pencarian mudah dimengerti.

\section{REFERENCES}

[1] D. H.S.SILALAHI, "PENCARIAN JUDUL LAGU ROHANI DALAM KIDUNG JEMAAT MENGGUNAKAN ALGORITMA MAXIMAL SHIFT DAN TURBO BOYER MOORE BERBASIS ANDROID," Repositori Institut USU, 2018.

[2] D. H. SILALAHI, "PENCARIAN JUDUL LAGU ROHANI DALAM KIDUNG JEMAAT MENGGUNAKAN ALGORITMA MAXIMAL SHIFT DAN TURBO BOYER MOORE BERBASIS ANDROID," Repositori Institusi USU, 2018.

[3] H. SISMORO, PENGANTAR LOGIKA INFORMATIKA, ALGORITMA, DAN PEMROGRAMAN KOMPUTER, YOGYAKARTA: ANDI, 2005. 
[4] HANDIKA, "ANALISIS PERBANDINGAN KINERJA PENCARIAN STRING DARI ALGORITMA MAXIMAL SHIFT , OPTIMAL MISHMATCH , DAN QUICK SEARCH," 2006.

[5] M. M. Dr. Ir. HASAN BASRI JUMIN, AGROEKOLOGI SUATU PENDEKATAN FISIOLOGIS, JAKARTA: PT. RAJAGRAFINDO PERSADA, 1992.

[6] R. A. S. A. M. SHALAHUDDIN, "REKAYASA PERANGKAT LUNAK TERSTRUKTUR DAN BERORIENTASI OBJEK," 2016.

[7] A. D. KASMAN, TRIK KOLABORASI ANDROID DENGAN PHP DAN MySQL, YOGYAKARTA: LOKOMEDIA, 2016.

[8] S. M. M. B. K. S. M. M. W. S. S. Seng Hansun, PEMROGRAMAN ANDROID DENGAN ANDROID STUDIO IDE, Giovanny, Ed., Yogyakarta: Penerbit ANDI (Anggota IKAPI), 2018. 